\title{
Correlation between Rock mass rating, Q-system and Rock mass index based on field data
}

\author{
Amine SOUFI ${ }^{1}$, Lahcen BAHI ${ }^{1}$, Latifa OUADIF $^{1}$, Jamal Eddine KISSAI $^{1}$ \\ ${ }^{1}$ Laboratory of Applied Geophysics, Geotechnics, Engineering Geology and the Environment, Mohammadia School of \\ Engineers, Mohammed V University, Rabat, Morocco
}

\begin{abstract}
Throughout the last decades, many authors have published empirical correlations between rock mass classification systems that have arisen from a series of measurements and observations with the special conditions of the work site; this means that the validity of these expressions is strongly dependent on the knowledge of the original data from which they were deduced. Consequently, none of these expressions are universal nowadays.

In recent years, the principal corps B3 "CPB3" of IMITER mine area has witnessed massive mining activities involving a large amount of underground excavation, the rock mass characteristics are undoubtedly the essential requirements for empirical design and numerical modeling. Therefore, the research carried out aims to provide a new specific inter-relation between the most widespread Quality Indexes, Bieniawski's RMR Quality Index, Barton's Q Quality Index and Palmström's RMi Mass index utilizing the data gathered from the jointed volcano-sedimentary rock mass of the "CPB3".

The "CPB3" mining level is located in Imiter silver mine, eastern Anti-Atlas, Morocco, at a depth of 500m. A total of 128 rock blocks were examined for the rock mass quality using the three characterization systems, the outcrop mapping was carried out on freshly parallel exposed faces in the horizontal south to north direction. After processing and plotting the in-situ measured data, several equations of the three indexes has been investigated using regression modeling to analyze the obtained results and find the most suitable equation with the highest correlation coefficients. These relationships were then compared with those reported in the literature.

The proposed regression models reveal strong correlations between RMR, Q and RMi indexes with high values of accuracy coefficients so that they can be used to estimate the "CPB3" underground rock mass quality for the range of RMR between $30 \%$ and $80 \%$. The developed mathematical formulations of the geomechanical indexes will certainly offer an effective tool to geologist and geotechnical professionals in the decision-making process, preliminary design phase, stability problems and suggestions of the required supporting system and techniques without the expense of more resources or time.
\end{abstract}

Key Words: Rock Mass Classification, RMR, RMi, Q-System, Correlation, Regression, Geomechanics

Table 1. Nomenclature used in this study

$\begin{array}{clcl}\text { CPB3 } & \text { Principal Corps B3 } & \sigma_{c} & \text { Uniaxial compressive strength of intact rock } \\ \text { RMR } & \text { Rock mass rating } & \mathrm{JP} & \text { Jointing parameter } \\ \text { RMi } & \text { Rock mass index } & \mathrm{jC} & \text { Joint condition factor } \\ \mathrm{Q} & \text { Rock mass quality } & \mathrm{Vb} & \text { Block volume, measured in } \mathrm{m}^{3} \\ \text { RQD } & \text { Rock quality designation } & \mathrm{jL} & \text { Joint size } \\ \mathrm{RA} & \text { Rating adjustment for joints orientation } & \mathrm{jR} & \text { Joint roughness } \\ \mathrm{Jn} & \text { Joint set number } & \mathrm{jA} & \text { Joint alteration } \\ \mathrm{Jr} & \text { Joint roughness number } & \mathrm{MAE} & \text { Mean absolute error } \\ \mathrm{Ja} & \text { Joint alteration number } & \text { RMSE } & \text { Root mean squared error } \\ \mathrm{Jw} & \text { Joint water reduction factor } & \text { MAPE } & \text { Mean absolute percent error } \\ \text { SRF } & \text { Stress reduction factor } & \text { Eq No } & \text { Equation number }\end{array}$




\section{Introduction}

The last five decades have witnessed the advent of several rock mass classification systems that became a very common practice in underground engineering to make an estimation of the geomechanical characteristics and provides input for stability analysis of the excavated zone to establish the appropriate support system.

Past experience with field examinations and monitoring has provided fairly good correlations with quantitative classifications and these may be used to predict engineering behavior of rock masses with reasonable accuracy. This is the reason that quantitative classifications have become very popular all over the world.

Nowadays, the most widely used classifications are Bieniawski's RMR Quality Index, Barton and al. Qsystem, and Palmström's Rock mass index.

\section{Rock mass classification systems}

\subsection{The Rock Mass Rating 1989}

Rock mass rating (RMR) was developed by Bieniawski [1], it is an index of rock mass competency based on the rating of six parameters:

$\mathrm{A}_{1} \quad$ Intact rock strength (IRS)

$\mathrm{A}_{2} \quad$ Rock quality designation (RQD)

$\mathrm{A}_{3} \quad$ Joint spacing (JS)

$\mathrm{A}_{4} \quad$ Joint surface condition (JC)

$\mathrm{A}_{5} \quad$ Groundwater condition (GW)

RA Rating adjustment for discontinuity orientation

The first five parameters represent the basic parameters in the classification system. Each of these parameters is given a value. All the values are algebraically summed for the first five given parameters and then adjusted by the sixth parameter depending on the joint and excavation orientation as shown in the following equations:

$$
\begin{aligned}
& R M R_{\text {basic }}=\sum_{i=1}^{5} A_{i} \\
& R M R_{89}=R M R_{\text {basic }}+R A
\end{aligned}
$$

The RMR value ranges from 0 to 100 .

\subsection{The Q-system 1993}

Barton and al. (1974) of the Norwegian Geotechnical Institute (NGI) proposed a Tunnelling Quality Index (Q) as a classification system for estimating rock support in tunnels [2,3]. It is a quantitative classification system based on a numerical assessment of the rock mass quality. Later, Barton and al. have published several papers on the Q system aiming at extending its applications.

The numerical value of the index $\mathrm{Q}$ is defined by six parameters and the following equation:
$Q=\left(\frac{R Q D}{J n}\right) \times\left(\frac{J r}{J a}\right) \times\left(\frac{J w}{S R F}\right)$

The symbols in the expressions above represent:

RQD Rock quality designation

Jn Joint set number

$\mathrm{Jr} \quad$ Joint roughness number

Ja Joint alteration number

Jw Joint water reduction factor

SRF Stress reduction factor

\subsection{The RMi system 1995}

The rock mass index is a volumetric parameter indicating the approximate uniaxial compressive strength of a rock mass, it was first presented by Palmström (1995) [3]. It makes use of the uniaxial compressive strength of intact rock $(\sigma)$ and the reducing effect of the joints penetrating the rock (JP) given as:

$R M i_{\text {jointed rock }}=\sigma_{c} \times J P=\sigma_{c} \times 0.2 \sqrt{j C} \times V b^{D}$

$j C=j L \times \frac{j R}{j A}$

$D=0.37 j C^{-0.2}$

The symbols in the expressions above represent:

$\sigma_{\mathrm{c}} \quad$ Uniaxial compressive strength of intact rock

JP Jointing parameter

jC Joint condition factor

$\mathrm{Vb}$ Block volume, measured in $\mathrm{m}^{3}$

jL Joint size

$\mathrm{jR} \quad$ Joint roughness

\section{Review of previous researchers}

Throughout the last decades, many authors have published empirical correlations. The most widely used examples are given in Table. 2

Table 2. Equations correlating geomechanical classifications

\begin{tabular}{|c|c|c|}
\hline Approach & Relation & $\mathrm{Eq}$ \\
\hline \multicolumn{3}{|c|}{ RMR-Q } \\
\hline Bieniawski (1984) [5] & $R M R=9 \cdot \ln (Q)+44$ & $(7)$ \\
\hline $\begin{array}{l}\text { Rutledge and Perston } \\
\text { (1978) [6] }\end{array}$ & $R M R=5,9 \cdot \ln (Q)+43$ & $(8)$ \\
\hline $\begin{array}{l}\text { Cameron Clarke and } \\
\text { Budavari (1981) [7] }\end{array}$ & $R M R=5 \cdot \ln (Q)+60,8$ & $(9)$ \\
\hline Abad and al. (1984) [8] & $\mathrm{RMR}=10,5 \cdot \ln (\mathrm{Q})+41,8$ & $(10)$ \\
\hline \multicolumn{3}{|c|}{ RMR-RMi } \\
\hline $\begin{array}{c}\text { Kumar and al. (2004) } \\
\text { [9] }\end{array}$ & $R M R=5,4 \cdot \ln (R M i)+54,4$ & $(11)$ \\
\hline $\begin{array}{l}\text { Hashemi and al. (2009) } \\
\text { [10] }\end{array}$ & $R M R=7,5 . R M i+36,8$ & $(12)$ \\
\hline \multicolumn{3}{|c|}{ RMi-Q } \\
\hline $\begin{array}{c}\text { Kumar and al. (2004) } \\
\text { [9] }\end{array}$ & $R M i=0,5 \cdot Q^{0,93}$ & $(13)$ \\
\hline
\end{tabular}
from previous works 


\begin{tabular}{|c|c|c|}
\hline $\begin{array}{c}\text { Hashemi and al. (2009) } \\
{[10]}\end{array}$ & $R M i=1,082 \cdot Q^{0,4945}$ & $(14)$ \\
\hline
\end{tabular}

Each of the previous expressions has arisen from a series of specific data that is related to a certain rock mass type.

\section{Methodology and case study}

The study area is located in Imiter silver mine, eastern Anti-Atlas, Morocco, at a depth of 500m.

- The common rock types in the "CPB3" are volcanosedimentary rock

- There are prominent foliations over all the rock mass in Est-West direction.

- There are multiple discontinuity sets, many of which intersect each other.

A total of 128 rock blocks were examined for the rock mass quality using the characterization systems from the previous discussion, the outcrop mapping was carried out on freshly exposed faces in the horizontal south to north direction.

After processing and checking the accuracy of the proposed expressions, several types of mathematical equations such as linear, exponential, logarithmic, and power were derived with regression analysis to find the most suitable expression with the highest correlation and lowest error coefficients.

\section{Statistical processing}

To analyze the results obtained, the $\mathrm{R}$ coefficient (Pearson's coefficient for correlation) was used. This coefficient provides information about the degree of relationship between two variables (RMR, Q, and RMi in this case). The mathematical formula for computing $\mathrm{R}$ is:

$R=\frac{n \sum x_{i} y_{i}-\left(\sum x_{i} \sum y_{i}\right)}{\sqrt{n\left(\sum x_{i}^{2}\right)-\left(\sum x_{i}\right)^{2}} \sqrt{n\left(\sum y_{i}{ }^{2}\right)-\left(\sum y_{i}\right)^{2}}}$

where, $x_{i}$ is the input parameter, $y_{i}$ is the output parameter and $\mathrm{n}$ is the number of data.

In order to check the representativeness of the proposed relationships, the Coefficient of Determination $\left(\mathrm{R}^{2}\right)$ is used to analyze the results, for example, if a certain correlation has a Coefficient of Determination of $\mathrm{X} \%$, it means that the X\% of the RMR Index is in direct relation to the Q-Index. So, it represents the proportion of the shared or explained variability.

MAE measures the average magnitude of the errors in the set of rock quality predictions, without considering their direction where all individual differences have equal weight. and is defined by the following expression:

$M A E=\frac{1}{n} \sum_{i=1}^{n}\left|A_{t}-F_{t}\right|$

where, $A_{t}$ is the actual value and $F_{t}$ is the forecast value of the output variable.

RMSE is a quadratic scoring rule that also measures the average magnitude of the error and tells how concentrated the data is around the line of best fit. The equation is given by:
$R M S E=\sqrt{\frac{1}{n} \sum_{i=1}^{n}\left(A_{t}-F_{t}\right)^{2}}$

MAPE is the measure of accuracy in statistics. It usually expresses accuracy as a percentage, and is defined by the following formula:

$M A P E=\frac{1}{n} \sum_{i=1}^{n}\left|\frac{A_{t}-F_{t}}{A_{t}}\right|$

\section{Correlation results between the rock mass classification systems}

\subsection{RMR-Q correlation}

The possibility of interrelating RMR and Q Indexes is studied using different types of mathematical expressions that are presented in Table. 3

Table 3. Comparison of various regression trendlines between $\mathrm{RMR}$ and $\mathrm{RMi}$

\begin{tabular}{|c|c|c|c|}
\hline Trend-line & Expression & $\mathrm{R}^{2}$ & $\begin{array}{c}\text { Eq. } \\
\text { No }\end{array}$ \\
\hline Linear & $R M R=1,4906 Q+$ & 0.29 & $(19)$ \\
\hline Multi & $\begin{array}{c}R M R=0,24 R Q D- \\
0,73 J n+7,66 J S- \\
0,2 J a+17,17 J w+ \\
19,83\end{array}$ & 0.79 & $(20)$ \\
Linear & $\begin{array}{c}\text { RMR }=44,953 \cdot e^{0,0304 . Q} \\
\text { Exponential }\end{array}$ & 0.27 & $(21)$ \\
\hline Logarithmic & $R M R=5,614 \cdot \ln (Q)+$ & 0.70 & $(22)$ \\
\hline
\end{tabular}

After testing different types of formulae for fitting, it could be concluded that the multilinear (Eq.20) and logarithmic (Eq.22) models fit well to the available data. By correlating the two sets of $Q$ values with the relevant RMR values, we obtained the figure. 1 


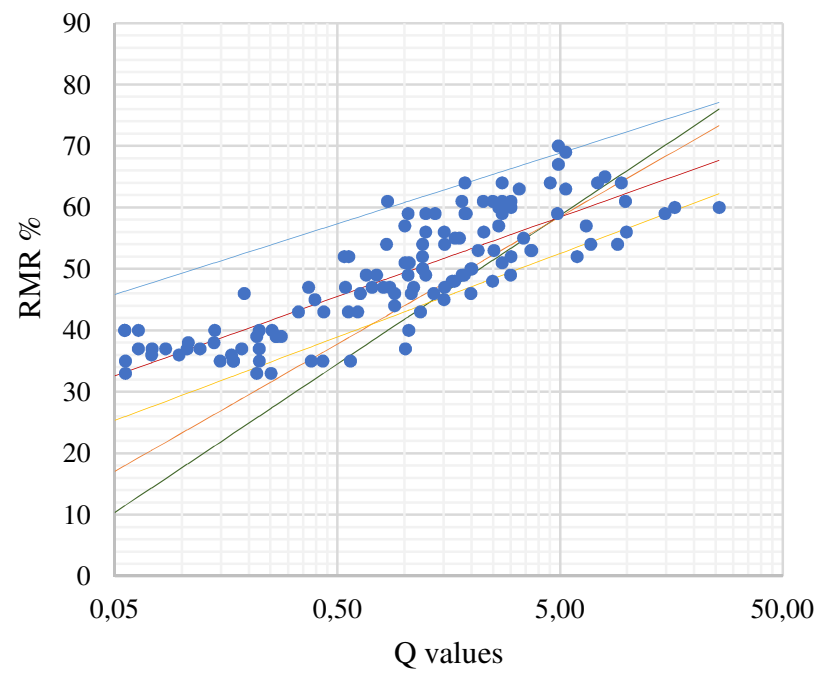

- Mesured data

RMR - Abad and al. (1984)

RMR - Bieniawski (1984)

RMR - Proposed logarithmic trendline (Eq.22)

RMR - Rutledge and preston (1978)

RMR - Cameron clarke and Budavari (1981)

Figure 1. plot of correlations between RMR and Q-system in this case and available literature

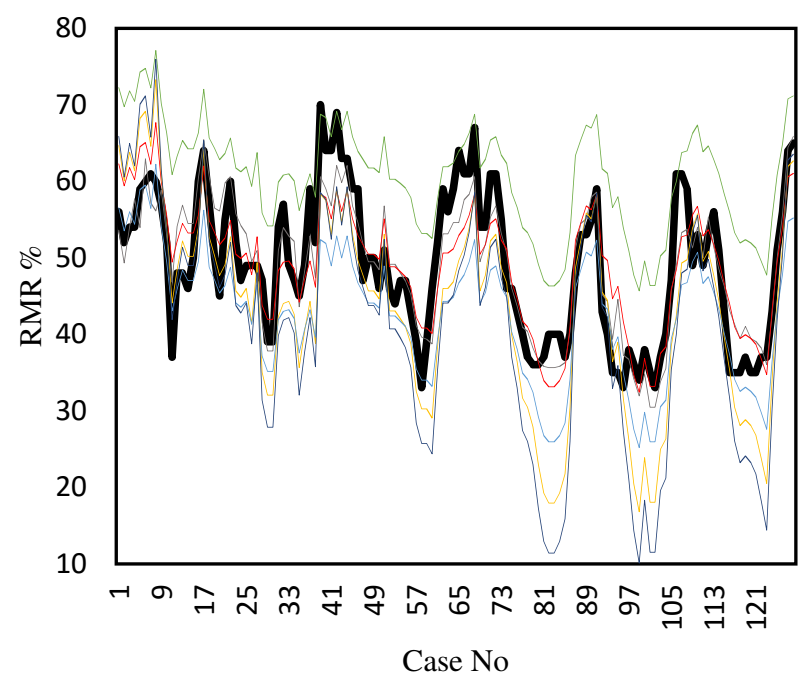

- RMR Mesured

Multiple regression expression (Eq.20)

RMR - Proposed logarithmic expression (Eq.22)

RMR - Bieniawski 1984

RMR - Rutledge and preston 1978

RMR - Cameron clarke and Budavari 1981

RMR - Abad and al 1984

Figure 2. Evaluation of various Correlations between RMR and $\mathrm{Q}$ in this case and available literature (128 cases)
Figure. 2 summarizes the obtained estimated RMR values from Q compared to other approaches shown in a graphical way

Table 4. Evaluation of correlation and accuracy Coefficients for existing and proposed RMR-Q relations

\begin{tabular}{|c|c|c|c|c|c|}
\hline Approach & $\mathrm{R}$ & MAE & RMSE & $\begin{array}{c}\text { MAPE } \\
(\%)\end{array}$ & $\begin{array}{l}\text { Eq } \\
\text { No. }\end{array}$ \\
\hline Bieniawski (1984) & 0,72 & 7,5 & 9,07 & 22,6 & (7) \\
\hline $\begin{array}{l}\text { Rutledge and } \\
\text { Perston (1978) }\end{array}$ & 0,72 & 6,91 & 8,3 & 17,14 & (8) \\
\hline $\begin{array}{l}\text { Cameron clarke } \\
\text { and Budavari } \\
(1981)\end{array}$ & 0,72 & 11,48 & 12,62 & 19,42 & (9) \\
\hline $\begin{array}{c}\text { Abad and al. } \\
\text { (1984) }\end{array}$ & 0,72 & 9,67 & 11,75 & 37,88 & (10) \\
\hline $\begin{array}{c}\text { Proposed } \\
\text { regression model }\end{array}$ & 0,72 & 4,34 & 5,26 & 8,81 & $(22)$ \\
\hline $\begin{array}{l}\text { Proposed multiple } \\
\text { regression model }\end{array}$ & 0,89 & 3,55 & 4,37 & 7,34 & $(20)$ \\
\hline
\end{tabular}

The results of accuracy analysis Table.4 show a satisfactory R and MAPE values for (Eq. 20) and (Eq. $22)$, the proposed RMR-Q relationships are given by:

$$
\begin{aligned}
& R M R=0,24 R Q D-0,73 J n+7,66 J s-0,2 J a+ \\
& 17,17 J w+19,83 \\
& R M R=5,614 \cdot \ln (Q)+49,39
\end{aligned}
$$

\subsection{RMR-RMi correlation}

The possibility of interrelating RMR and RMi Indexes is studied using different types of mathematical expressions that are presented in table. 5

Table 5. Comparison of various regression trendlines between RMR and RMi

\begin{tabular}{|c|c|c|c|}
\hline Trend-line & Expression & $\mathrm{R}^{2}$ & $\begin{array}{c}\text { Eq. } \\
\text { No }\end{array}$ \\
\hline Linear & $\begin{array}{c}R M R=8,2667 \cdot R M i+ \\
41,77\end{array}$ & 0,60 & $(23)$ \\
\hline Multi & $\begin{array}{c}R M R=-0,52 F- \\
6,32 J S-0,04 J a+ \\
0,19 j L+5,96 V b+ \\
3,13 j C-84,86 D+ \\
107,62\end{array}$ & 0,87 & $(24)$ \\
Linear & $\begin{array}{c}R M R \\
\text { Exponential }\end{array}$ & 0,58 & $(25)$ \\
\hline Logarithmic & $\begin{array}{c}R M R=7,71 \cdot \ln (R M i)+ \\
54,441\end{array}$ & 0,83 & $(26)$ \\
\hline
\end{tabular}

Based on the analysis of the coefficient of determination, the most approximate formulas are the multi-linear (Eq.24) and logarithmic (Eq.26) models.

The obtained results from the correlation between RMi and RMR values are shown in an analytical way by figure. 3 


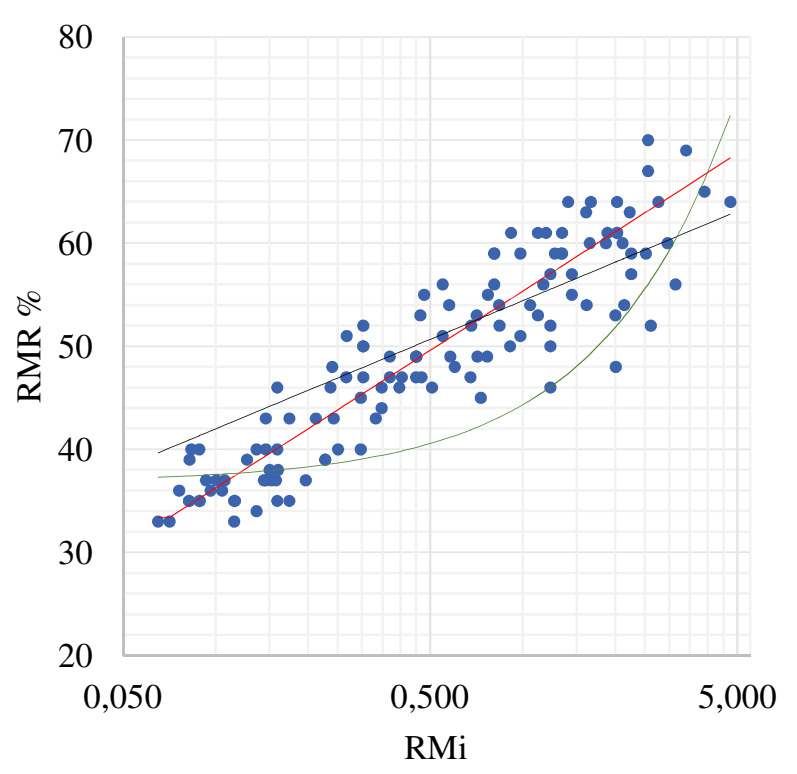

- Mesured data

RMR - Proposed logarithmic trendline (Eq.26)

- RMR Kumar and al. (2004)

_ RMR Hashemi and al. (2009)

Figure 3. plot of correlations between RMR and RMi in this case and available literature

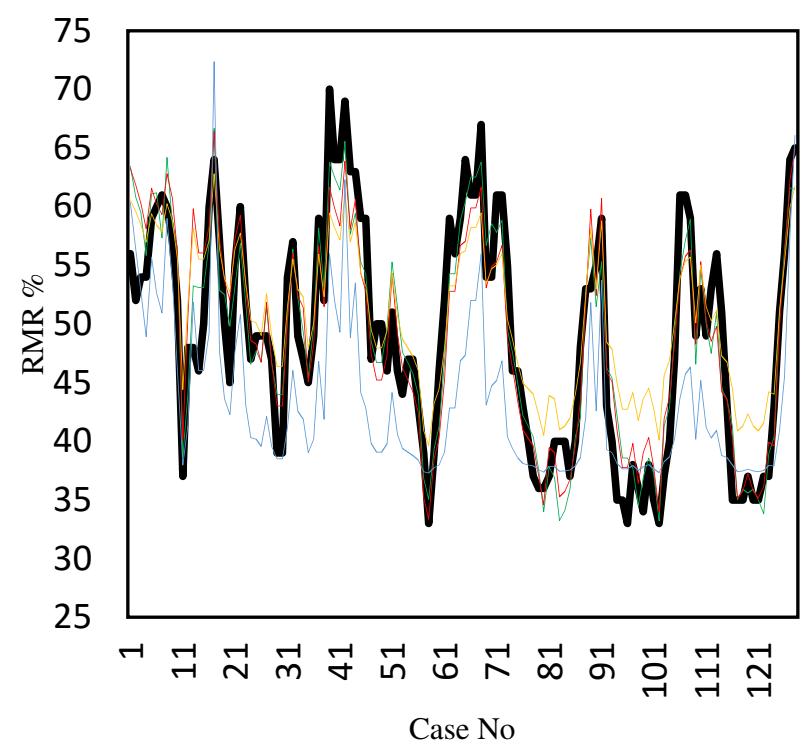

RMR Mesured

Multiple regression model (Eq.24)

— Proposed logarithmic expression (Eq.26)

RMR Kumar and al,2004

RMR Hashemi and al 2009

Figure 4. Evaluation of various Correlations between RMR and $\mathrm{RMi}$ in this case and available literature (128 cases)
Figure.4 summarizes the obtained estimated RMR values from RMi compared to other approaches shown in a graphical way

Table 6. Evaluation of correlation and accuracy Coefficients for existing and proposed RMR-RMi relations

\begin{tabular}{|c|c|c|c|c|c|}
\hline Approach & $\mathrm{R}$ & MAE & RMSE & $\begin{array}{l}\text { MAPE } \\
(\%)\end{array}$ & $\begin{array}{l}\text { Eq } \\
\text { No. }\end{array}$ \\
\hline $\begin{array}{l}\text { Kumar and al. } \\
\text { (2004) }\end{array}$ & 0,89 & 4,2 & 4,95 & 56 & (11) \\
\hline $\begin{array}{l}\text { Hashemi and al. } \\
\text { (2009) }\end{array}$ & 0,81 & 6,77 & 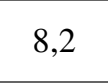 & 15,47 & (12) \\
\hline $\begin{array}{c}\text { Proposed } \\
\text { regression model }\end{array}$ & 0,89 & 3,09 & 3,99 & 6,17 & (26) \\
\hline $\begin{array}{l}\text { Proposed multiple } \\
\text { regression model }\end{array}$ & 0,93 & 2,88 & 3,49 & 5,93 & (24) \\
\hline
\end{tabular}

It can be seen clearly in Table. 6 that the estimated value of RMR from RMi using logarithmic and multi-Linear expressions shows one of the biggest values for $\mathrm{R}$ and lowest MAPE, the resultants equations for the regression are:

$R M R=-0,52 F-6,32 J s-0,04 J a+0,19 j L+$

$5,96 \mathrm{Vb}+3,13 j \mathrm{C}-84,86 \mathrm{D}+107,62$

$R M R=7,71 \cdot \ln (R M i)+54,44$

\subsection{RMi-Q correlation}

The possibility of interrelating RMi and Q Indexes is studied using different types of mathematical expressions that are presented in table. 7

Table 7. Comparison of various regression trendlines between RMi and Q

\begin{tabular}{|c|c|c|c|}
\hline Trend-line & Expression & $\mathrm{R}^{2}$ & $\begin{array}{c}\text { Eq. } \\
\text { No }\end{array}$ \\
\hline Linear & $R M i=0,1962 Q+0,444$ & 0.55 & $(27)$ \\
\hline Multi & $\begin{array}{c}R M i=0,021 R Q D- \\
0,054 J n+0,445 J s- \\
0,129 J a+0,065 J w+ \\
0,674\end{array}$ & 0.71 & $(28)$ \\
\hline Exponential & $R M i=0,3121 \cdot e^{0,2092 \cdot Q}$ & 0.41 & $(29)$ \\
\hline Logarithmic & $\begin{array}{c}R M i=0,5073 \cdot \ln (Q)+ \\
0,9122\end{array}$ & 0,63 & $(30)$ \\
\hline Power & $R M i=0,5195 \cdot Q^{0,7202}$ & 0,82 & $(31)$ \\
\hline
\end{tabular}

Likewise, a similar analysis was performed for RMi and Q correlation, it could be concluded that the power model (Eq.26) model fits well to the available data.

RMi-Q Correlated data from the "CPB3", along with the other correlations available in the literature, are presented in Figure. 5 


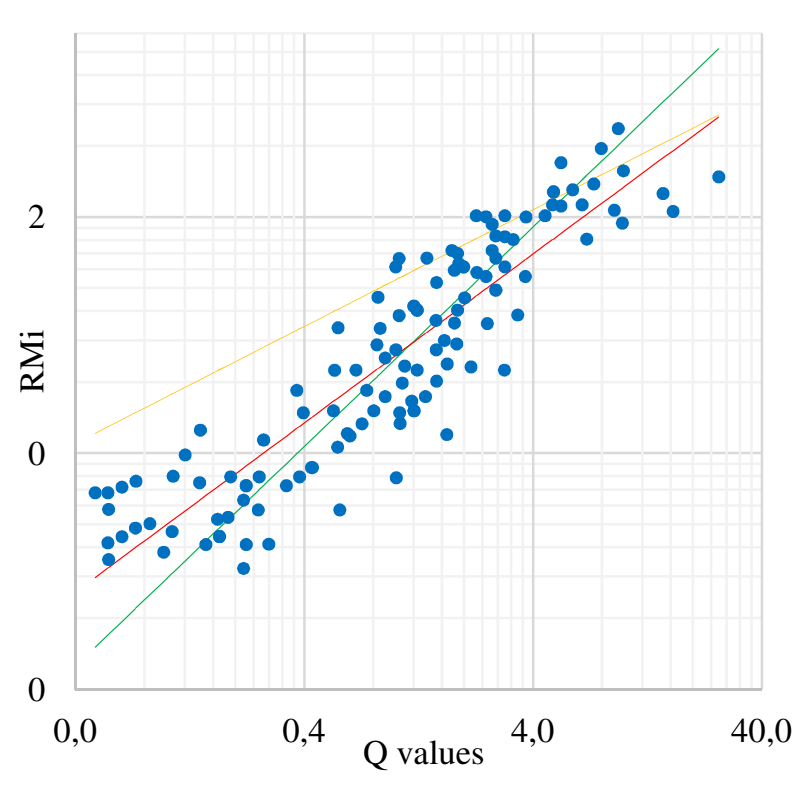

- Mesured data

- Rmi Kumar and al. (2004)

Rmi - Proposed power trendline (Eq.31)

Rmi Hashemi and al. (2009)

Figure 5. plot of various correlations between RMi and Qsystem in this case and available literature

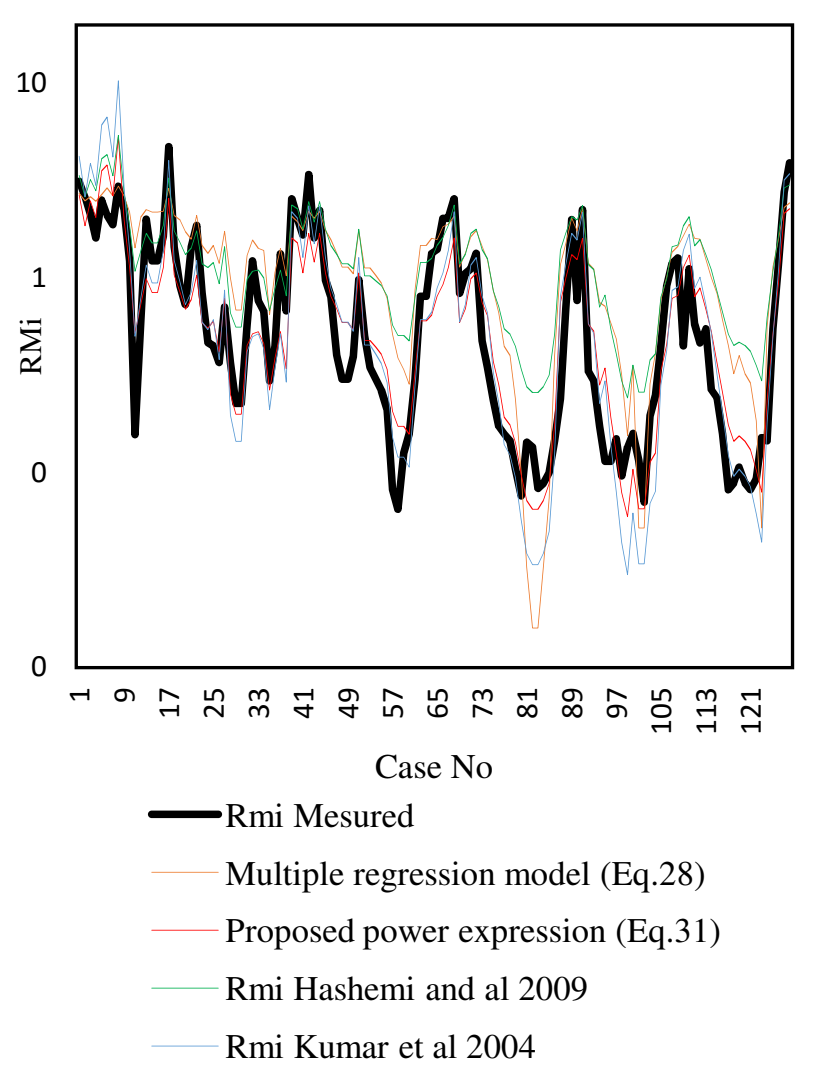

Figure 6. Evaluation of various Correlations between RMi and $\mathrm{Q}$ in this case and available literature (128 cases)
Figure.6 summarizes the obtained estimated RMi values from Q compared to other approaches shown in a graphical way

Table 8. Evaluation of correlation and accuracy Coefficients for existing and proposed RMi-Q relations

\begin{tabular}{|c|c|c|c|c|c|}
\hline Approach & $\mathrm{R}$ & $\mathrm{MAE}$ & $\mathrm{RMSE}$ & $\begin{array}{c}\text { MAPE } \\
(\%)\end{array}$ & $\begin{array}{c}\mathrm{Eq} \\
\text { No. }\end{array}$ \\
\hline $\begin{array}{c}\text { Kumar and al. } \\
\text { (2004) }\end{array}$ & 0,93 & 0,52 & 0,66 & 47,93 & $(13)$ \\
\hline $\begin{array}{c}\text { Hashemi and al. } \\
\text { (2009) }\end{array}$ & 0,72 & 0,39 & 0,94 & 53,21 & $(14)$ \\
\hline $\begin{array}{c}\text { Proposed } \\
\text { regression model }\end{array}$ & 0,98 & 0,33 & 0,53 & 43,01 & $(31)$ \\
\hline $\begin{array}{c}\text { Proposed multiple } \\
\text { regression model }\end{array}$ & 0,84 & 0,52 & 0,63 & 60,40 & $(28)$ \\
\hline
\end{tabular}

From a statistical point of view, the power law approximation gives a quite acceptable level of certainty Table.8, we have got the following equation:

$R M i=0,5195 . Q^{0,7202}$

Table 9. The recommended relations based on the "CPB3" data

\begin{tabular}{|c|c|c|}
\hline Expression & $\mathrm{R}$ & Eq No. \\
\hline \multicolumn{3}{|l|}{$\mathrm{RMR}-\mathrm{Q}$} \\
\hline $\begin{array}{c}R M R=0,24 R Q D-0,73 J n+ \\
7,66 J s-0,2 J a+17,17 J w+19,83\end{array}$ & 0.89 & $(20)$ \\
\hline$R M R=5,614 \cdot \ln (Q)+49,395$ & 0.72 & (22) \\
\hline \multicolumn{3}{|l|}{ RMR $-\mathrm{RMi}$} \\
\hline $\begin{array}{c}R M R=-0,52 F-6,32 J s- \\
0,04 J a+0,19 j L+5,96 V b+ \\
3,13 j C-84,86 D+107,62\end{array}$ & 0.93 & $(24)$ \\
\hline$R M R=7,71 \cdot \ln (R M i)+54,441$ & 0.89 & (26) \\
\hline \multicolumn{3}{|l|}{$\mathrm{RMi}-\mathrm{Q}$} \\
\hline$R M i=0,5195 \cdot Q^{0,7202}$ & 0.98 & (31) \\
\hline
\end{tabular}

\section{Conclusion}

Most of the available relationships between indexes of rock mass quality have been derived using geological data of Europe, America and Oceania region. In recent years, the "CPB3" of IMITER site has witnessed massive mining activities involving a large amount of underground excavation. Therefore, there is a need to develop specific correlations between the most prevalent rock mass classification indexes for the special conditions of the working site.

The systematic plotting of the graphs using the available relationships reveals a strong potential correlation between RMR, Q and RMi indexes. The proposed regression equations have high-reliability coefficient Table.9 so that they can be used to estimate the "CPB3" underground rock mass quality for the range of RMR between $30 \%$ and $80 \%$.

After a preliminary comparison of the different solutions, we recommend using these correlations with extreme prudence at initial stages of a project, being extremely cautious about the origin, compatibility and rating range of the initial data. 


\section{References}

1. Z.T. Bieniawski, Classification of Rock Masses for Engineering: The RMR System and Future Trends, Comprehensive rock engineering, 3,522-542, (1993)

2. N. Barton, R. Lien, and J. Lunde, Engineering classification of rock masses for the design of tunnel support, (1974)

3. N. Barton, International Journal of Rock Mechanics \& Mining Sciences, Some new $Q$-value correlations to assist site characteristics and tunnel design, 185216, (2002)

4. A. Palmström, Journal of Rock Mechanics and Tunnelling Technology, The Rock Mass Index (RMi) applied in rock mechanics and rock engineering, 11, No.2, 1-40, (1996)

5. Z.T. Bieniawski, Rock Mechanics Design in Mining and Tunnelling,272,(1984)

6. J.C. Rutledge, R.L. Perston, Experience with engineering classifications of rock, In Proc. Int. Tunneling Sym, Tokyo, (1978)

7. I.S Cameron-Clarke, S. Budavari, Engineering Geology, Correlation of rock mass classification parameters obtained from bore core and in situ observations, 19-53, (1981)

8. J. Abad, B. Caleda, E.Chacon, V.Gutierrez, E. Hidlgo, Application of geomechanical classification to predict the convergence of coal mine galleries and to design their supports, In 5th Int. Congress on Rock Mech., Melbourne, 15-19.(1984)

9. N. Kumar, NK. Samadhiya, R. Anbalagan, Int J Rock Mech, Application of rock mass classification system for tunneling in Himalaya, Paper 3B 14, SINOROCK2004 Symposium, (2004)

10. M. Hashemi, Sh. Moghddas, R. Ajalloeian, Rock Mech Rock Eng, Application of Rock Mass Characterization for Determining the Mechanical Properties of Rock Mass: a Comparative Study, 305320, (2010) 